\title{
Effect of Elevated Temperature on Engineering Properties of Ternary Blended No-cement Mortar
}

\author{
Harry Hermawan ${ }^{1}$, Ta-Peng Chang ${ }^{1}$, Herry Suryadi Djayaprabha ${ }^{1,2}$ and Hoang-Anh Nguyen ${ }^{3}$ \\ ${ }^{1}$ Department of Civil and Construction Engineering, National Taiwan University of Science and Technology, Taipei 106, Taiwan \\ ${ }^{2}$ Department of Civil Engineering, Parahyangan Catholic University, Bandung 40141, Indonesia \\ ${ }^{3}$ Department of Rural Technology, College of Rural Development, Can Tho University, Can Tho City 90000, Vietnam
}

\begin{abstract}
This paper aims to examine the engineering properties of ternary blended no-cement mortar which subjected to the various elevated temperatures exposure. The mortars were produced by mixing ground granulated blast furnace slag (S), Type-F fly ash (F) and circulating fluidized bed combustion (CFBC) fly ash (C). The water-tobinder ratio was fixed at 0.40 and the CFBC fly ash content was fixed at $15 \mathrm{wt} . \%$ of the mixture that acts as the main activator. The specimens were exposed to the elevated temperatures ranging from $200{ }^{\circ} \mathrm{C}$ to $800{ }^{\circ} \mathrm{C}$. The mass loss, compressive strength, and ultrasonic pulse velocity were determined before and after exposure to the elevated temperatures. The obtained results showed after exposed to high temperature, the mortar weight reduction was discovered in the range of $6.0-8.7 \%$ when temperature rose from $200{ }^{\circ} \mathrm{C}$ to $600{ }^{\circ} \mathrm{C}$, and decreased significantly up to $12.4 \%$ as temperature reached $800{ }^{\circ} \mathrm{C}$. The major strength loss occurred after $600{ }^{\circ} \mathrm{C}$ with the residual compressive strength approximately at $44.2 \%$. At $200{ }^{\circ} \mathrm{C}$, increased strength was found on SFC mixture and when temperature rose to $400{ }^{\circ} \mathrm{C}$, the specimens still can resist the load reliably with the strength loss less than $8.0 \%$. Consequently, SFC mortar generates good durability and heat resistance below $400{ }^{\circ} \mathrm{C}$.
\end{abstract}

\section{Introduction}

Nowadays, the production of Portland cement is the main issue that needs to be solved due to the $\mathrm{CO}_{2}$ emission from the cement plant was produced in the huge amount. Thus, researchers geared to develop the new alternative pozzolanic material in order to replace the Portland cement that is environmental friendly beside lower cost, the required potential energy to produce it can be reduced and did not create the emission with the substantial extent. The use of industrial wastes is one of the alternative approaches to reduce the use of Portland cement. Example of these wastes includes ground granulated blast furnace slag (GGBFS), fly ash (FA), and circulating fluidized bed combustion (CFBC) fly ash. The utilization of fly ash and slag as the basis material to replace the ordinary Portland cement (OPC) has been investigated with the major formation of ettringite $(\mathrm{AFt})$ and calcium silicate hydrate $(\mathrm{C}-\mathrm{S}-\mathrm{H})$ gel.

CFBC fly ash is the current new material that has been proposed and developed by some researcher. This particular fly ash was produced from the thermal power plant with the clean coal combustion technology that releases fly ash and bottom ash that contains physicochemical properties and acts as the main activator to trigger the binding mechanism. The aforementioned technology was considered as the environmental-friendly technology that has many advantages such as low $\mathrm{SO}_{2}$ and $\mathrm{NO}_{\mathrm{x}}$ emissions, high combustion efficiency, wide fuel flexibility and low combustion temperatures (typically in the range of $800-900{ }^{\circ} \mathrm{C}$ ) [1]-[5]. The CFBC fly ash theoretically includes calcium oxide $(\mathrm{CaO})$ and sulfur trioxide $\left(\mathrm{SO}_{3}\right)$ and mostly formed in the irregular shape. High content of free lime and $\mathrm{CaSO}_{4}$ were found in the CFBC fly ash particle that induces the setting and hardening process if it contacts with the aqueous solution which characterized by self-cementing behavior. The main hydration products of CFBC fly ashes are hydrated calcium silicate $(\mathrm{C}-\mathrm{S}-\mathrm{H})$, ettringite $(\mathrm{AFt})$, gypsum and some portlandite [1]-[8].

Several studies [1]-[8] have focused on adding the CFBC fly ash in an effort to enhance the mechanical properties such as compressive strength, durability, Young's modulus, shear modulus, etc. Chen et al. [1] reported that the optimum value for no-cement SFC binder to obtain the best compressive strength is about 15-20 wt.\% CFBC fly ash and 10-30 wt.\% FA as replacement of GGBFS. For SFC pastes with the waterto-binder ratio of 0.35 , the compressive strengths at 3 and 28 days can reach $47.7 \mathrm{MPa}$ and $68.4 \mathrm{MPa}$, respectively. In other work, the SFC binder has been proposed by Nguyen et al. [6] in producing the high strength selfcompacting concrete (SCC). In contrast, the utilization of CFBC fly ash in the mortar can significantly increase the sulfate resistance [2], [8]. However, several studies [4], [5] confirmed that the CFBC fly ash replacement leads to 
increase length change (expansion) and the amount of CFBC fly ash replacement cement was recommended to be limited below $20 \%$.

Generally, concrete provides the good fire resistance properties due to its constituent materials (i.e., binder and aggregates). The strength of concrete has significant influence on its properties at both room and high temperatures. When the concrete was subjected to fire, the spalling phenomenon occurred where the surface cracks and breaks into smaller pieces as the concrete deteriorates at the elevated temperature [9]. Horszczaruk et al. [10] stated that at high temperature, there was transformation in mechanical properties of paste and aggregates within the concrete since calcium hydroxide $(\mathrm{CH})$ decomposes into lime and water in the temperature range of $350-550{ }^{\circ} \mathrm{C}$ and the chemical compound calcium silicate hydrate $(\mathrm{C}-\mathrm{S}-\mathrm{H})$ gel completely dehydrates and decomposes in the range of 700-900 ${ }^{\circ} \mathrm{C}$. Nadeem et al. [11] reported that the major strength and durability loss of fly ash mortar occurred after $400{ }^{\circ} \mathrm{C}$ where the strength loss was up to $16 \%$ and the strength loss was even higher for about $46 \%$ and $80 \%$ at elevated temperatures of $600{ }^{\circ} \mathrm{C}$ and $800{ }^{\circ} \mathrm{C}$, respectively. However, for the performance of using CFBC fly ash in the mortar, no more details have been reported and this suggests that there is not yet a full understanding of the impact of the elevated temperature exposure on the properties of SFC mortar. This present paper aims to investigate the durability of SFC mortar subjected to the elevated temperatures through various experiments which assess the mass loss, compressive strength, ultrasonic pulse velocity and thermal conductivity.

\section{Experimental program}

\subsection{Materials and mix proportions}

Three industrial waste by-products of ground granulated blast furnace slag (S), class F fly ash (F) and CFBC fly ash (C) were used as binder in this study. Its chemical and physical properties are given in Table 1. The commercial Type I Portland cement in accordance to ASTM C150 was used as the reference binder. Natural river sand was used as fine aggregate with the specific gravity at saturated surface dry condition (SSD) of 2.716 and the water absorption of sand is $0.78 \%$.

The mix proportion of SFC mortar is provided in Table 2. The independent variable of CFBC fly ash content was determined. Chen et al. [1] pointed out that the additional of CFBC fly ash from the total binder weight of mixture $(\mathrm{S}+\mathrm{F})$ in the range of $15-20 \mathrm{wt} . \%$ can improve the compressive strength and trigger the hydration process. In fact, the higher amount of CFBC fly ash results in the discontinuous structure of the SFC binder due to the secondary gypsum and delayed AFt formation. Consequently, the CFBC fly ash content was fixed at $15 \%$ by total weight of slag and class $\mathrm{F}$ fly ash. The binders were prepared by dry mixing of pozzolanic materials with 4 different class $\mathrm{F}$ fly ash to binder ratios, i.e., $\mathrm{F} /(\mathrm{S}+\mathrm{F})=0,0.1,0.3$ and 0.5 with the CFBC fly ash addition, i.e., $\mathrm{C} /(\mathrm{S}+\mathrm{F})=0.15$. The water-to-binder ratio was fixed at 0.40 for all mixtures. In order to produce the SFC mortar, the sand-to-binder ratio was fixed at 2.75 in accordance with ASTMC109/C109M. Superplasticizer was added into the mixture at certain amount during the mixing process in order to obtain the desired workability.

Table 1. Properties of the binder materials.

\begin{tabular}{lrrrr}
\hline & $\begin{array}{c}\text { Portland } \\
\text { Cement }\end{array}$ & GGBFS & $\begin{array}{c}\text { Class F } \\
\text { fly ash }\end{array}$ & $\begin{array}{c}\text { CFBC } \\
\text { fly ash }\end{array}$ \\
\hline Chemical composition (\%) & & & & \\
$\mathrm{SiO}_{2}$ & 20.42 & 33.54 & 59.98 & 5.22 \\
$\mathrm{Al}_{2} \mathrm{O}_{3}$ & 4.95 & 13.00 & 25.38 & 2.21 \\
$\mathrm{Fe}_{2} \mathrm{O}_{3}$ & 3.09 & 0.50 & 3.65 & 0.58 \\
$\mathrm{CaO}$ & 61.96 & 39.85 & 5.72 & 56.80 \\
$\mathrm{MgO}$ & 3.29 & 6.90 & 1.26 & 2.06 \\
$\mathrm{SO}_{3}$ & 2.40 & 1.67 & 0.26 & 32.40 \\
$\mathrm{~K}_{2} \mathrm{O}$ & - & - & 0.48 & - \\
$\mathrm{TiO}_{2}$ & - & - & 1.46 & - \\
$\mathrm{L} . \mathrm{O} . \mathrm{I}$ & 1.75 & 4.54 & 3.00 & - \\
& & & & \\
Physical properties & & & & \\
Specific gravity & 3.15 & 2.9 & 2.17 & 2.7 \\
Blaine fineness $\left(\mathrm{cm}^{2} / \mathrm{g}\right)$ & 3450 & 6000 & - & 3000 \\
\hline
\end{tabular}

Table 2. Mix proportions of SFC mortar (unit: $\mathrm{kg} / \mathrm{m}^{3}$ ).

\begin{tabular}{lcccccccc}
\hline Mixture & Cement GGBFS & $\begin{array}{c}\text { Class F } \\
\text { fly ash }\end{array}$ & $\begin{array}{c}\text { CFBC } \\
\text { fly ash }\end{array}$ & Sand & Water & SP \\
\hline OPC & 578.04 & - & - & - & 1589.61 & 231.22 & 0.83 \\
S100F0C15 & - & 493.88 & - & 74.08 & 1561.90 & 227.19 & 0.54 \\
S90F10C15 & - & 441.80 & 49.09 & 73.63 & 1552.44 & 225.81 & 0.53 \\
S70F30C15 & - & 339.51 & 145.51 & 72.75 & 1533.87 & 223.11 & 0.66 \\
S50F50C15 & - & 239.64 & 239.64 & 71.89 & 1515.73 & 220.47 & 1.15 \\
\hline
\end{tabular}

\subsection{Specimen preparation and testing methods}

The mixtures were casted into a 50-mm cubic mold and sealed with the plastic wrap to prevent the water evaporation then after $24 \mathrm{~h}$, all specimens were removed from the molds and cured at a temperature of $25 \pm 2{ }^{\circ} \mathrm{C}$ and relative humidity level of $65 \%$ until the day of testing. The engineering properties of SFC mortar were investigated by mass loss, compressive strength, ultrasonic pulse velocity (UPV) and thermal conductivity tests. The compressive strength test was conducted in accordance with ASTM C109. Evaluation of nondestructive testing method was examined thoroughly by applying the ultrasonic waves and heat transfer through the specimen. The ultrasonic pulse velocity was conducted by UPV test instrument (PROCEQ Pundit Lab) with the nominal transducer frequency of $54 \mathrm{kHz}$ in accordance with ASTM C597, and the thermal conductivity was conducted by heat transfer analyzer (ISOMET model 2104) with the specific surface probe for thermal conductivity measurement range between 0.30 and $2.0 \mathrm{~W} / \mathrm{m} \cdot \mathrm{K}$ and temperature between -15 and $50{ }^{\circ} \mathrm{C}$. Two series of experimental works were conducted, 
i.e. the specimens were tested before and after subjected to elevated temperatures. Before exposed to elevated temperatures, the compressive strengths of mortar from each mixture were measured at 3, 7, 14 and 28 days using 200 tons uniaxial compression testing machine. Moreover, the measurement of the UPV and thermal conductivity were also carried out before exposed to the elevated temperatures. The other mortar specimens were prepared to be subjected to the elevated temperature exposure of $200{ }^{\circ} \mathrm{C}, 400{ }^{\circ} \mathrm{C}, 600{ }^{\circ} \mathrm{C}$, and $800{ }^{\circ} \mathrm{C}$ only at age of 28 days. The specimens were heated up in the high temperature electric furnace with a thermostat to control the rate of heating. The heating rate was set at $5{ }^{\circ} \mathrm{C} / \mathrm{min}$ and the temperature increased progressively until it reached the desired temperature and maintained for 60 min. Furthermore, in order to prevent the specimens from the thermal shock, the specimens were taken after cooled down until reached the uniform room temperature. After the specimens were subjected to elevated temperatures, the measurement of mass loss, UPV and compressive strength were carried out.

\section{Results and discussions}

\subsection{Development of mortar properties before elevated temperature exposure}

The investigation of compressive strength, ultrasonic pulse velocity (UPV) and thermal conductivity were established in order to measure the development of engineering mortar properties. Fig. 1 presents the experimental results for the compressive strength test result of OPC and SFC mortars. The compressive strength of OPC mortar was obviously higher than the SFC mortar however the strength was also considerable. The compressive strengths of SFC mortar with the 0-30\% FA were higher than those SFC mortar with 50\% FA. The increased FA of $50 \%$ exhibited the decreased compressive strength up to $35 \%$. Moreover, the $10 \%$ slag replacement by fly ash with the fixed CFBC fly ash content of $15 \%$ in the S90F10C15 mixture achieves the highest compressive strength of $22 \mathrm{MPa}$ and $30 \mathrm{MPa}$ at 3 and 28 days, respectively compared with the other SFC mixtures. This results show the good agreement with the research conducted by Chen et al. [1].

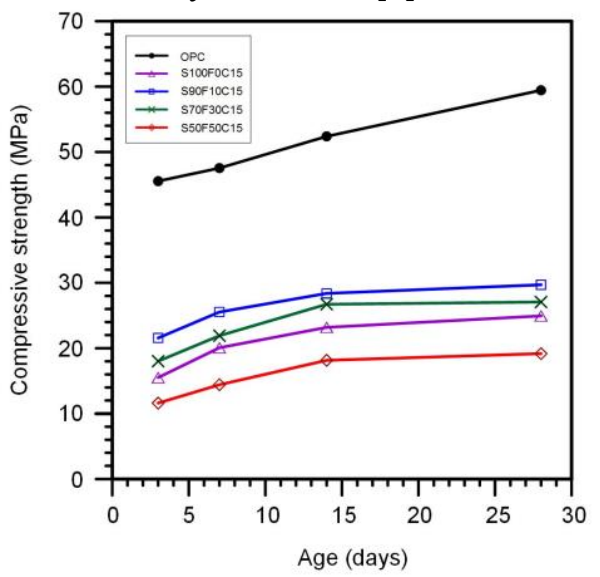

Figure 1. Compressive strength development of mortars.
The UPV results of mortars are given in Fig. 2. Generally, the UPV evaluates the compactness of specimens by measuring the passing speed and attenuation of an ultrasonic wave. Based on the test results, the higher compressive strengths resulted in higher UPV values for all mortars. The development of UPV was equivalent starting from 3 up to 28 days for OPC mortar, however the SFC mortars induced the substantial increment. The huge increment was shown by S90F10C15 and S50F50C15 mixtures at approximately $4 \%$. As 15\% CFBC fly ash fixed amount was used, SFC mortar composed of $10 \%$ FA had the UPV value comparable with the OPC mortars at 28 days. The result suggested the replacement of slag should be limited in order to obtain the dense microstructure of mortars.

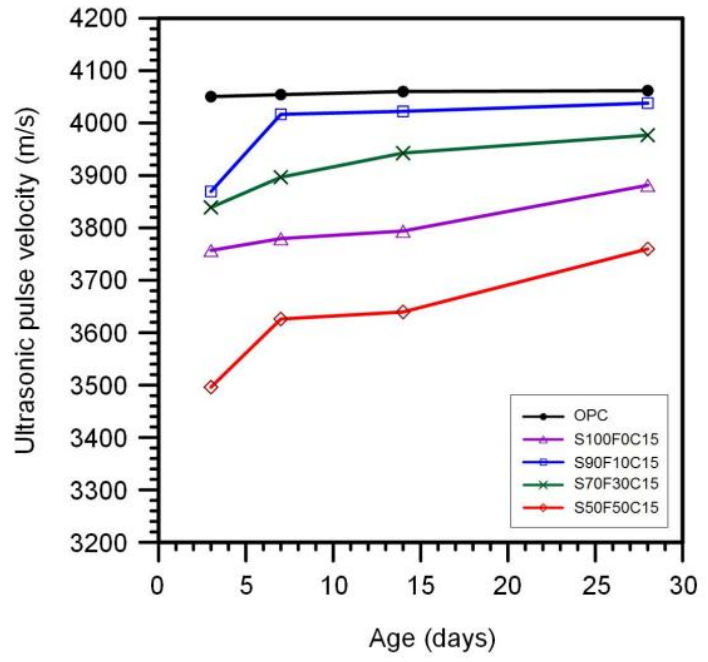

Figure 2. Ultrasonic pulse velocity of SFC mix proportions.

The thermal conductivity of the mortars at 28 days is summarized in Table 3. The mortar with longer hydration age exhibits higher value of thermal conductivity as more amount of solid phase formed. As the replacement ratio of the slag for the fly ash increased from 0 to $10 \%$, the thermal conductivity increased from $1.21 \mathrm{~W} /(\mathrm{m} \cdot \mathrm{K})$ to $1.52 \mathrm{~W} /(\mathrm{m} \cdot \mathrm{K})$. However, the increase of the slag replacement ratio by the fly ash in the range of $10-50 \%$, the thermal conductivity of mortars decreased simultaneously. Accordingly, specimen with the low thermal conductivity represents the weak heat transfer and high probability of porosity occurred with the high air content.

Table 3. Thermal conductivity examination at 28 days

\begin{tabular}{lccccc}
\hline Mixture & OPC & S100F0C15 & S90F10C15 & S70F30C15 & S50F50C15 \\
\hline $\begin{array}{l}\text { Thermal } \\
\text { conductivity } \\
(\mathbf{W} /(\mathbf{m} \cdot \mathbf{K}))\end{array}$ & 1.65 & 1.21 & 1.52 & 1.36 & 1.24 \\
\hline
\end{tabular}

\subsection{Mass loss}

The weight of mortar decreased with increasing temperature due to the release of water from the cement paste caused the air voids formed in the inner part of mortar. The mortar integrity disintegrates as demonstrated by the increase of weight reduction with increased temperature. In this present study, the mass 
losses of SFC mortar were slightly higher than the mass losses in OPC mortar except S50F50C15 mixture above $200{ }^{\circ} \mathrm{C}$. The average mass losses of SFC mortar exposed to $200{ }^{\circ} \mathrm{C}, 400{ }^{\circ} \mathrm{C}, 600{ }^{\circ} \mathrm{C}$, and $800{ }^{\circ} \mathrm{C}$ were $6.6 \%, 7.6 \%$, $8.0 \%$ and $12.0 \%$, respectively. When temperature rises from 200 to $600{ }^{\circ} \mathrm{C}$, the mass loss for both mortar types is sufficiently small in the range of $6.0-8.7 \%$, however it increased dramatically around $12.4 \%$ after exposed to $800{ }^{\circ} \mathrm{C}$. Fig. 3 shows that the mass loss tends to increase in SFC mortar when the slag content was replaced up to $30 \%$, moreover the increased FA of $50 \%$ contributed lower weight reduction compared with all of mortar types.

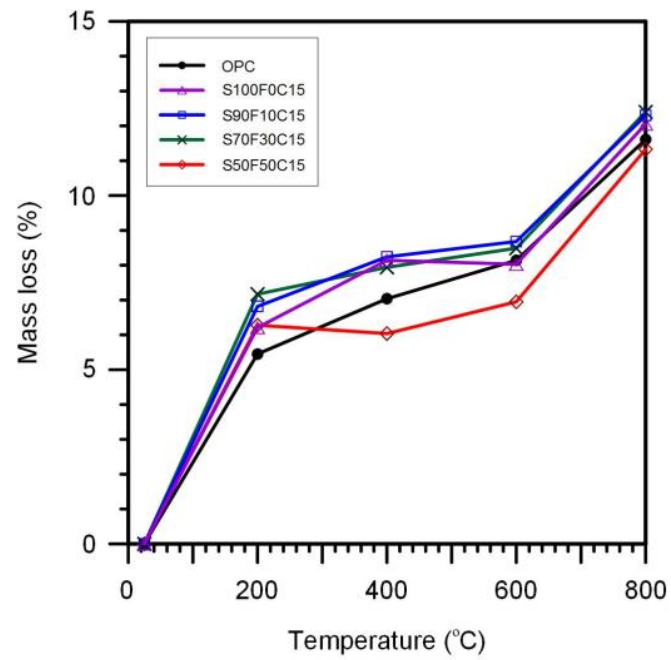

Figure 3. Mass losses of the mortar specimens.

\subsection{Ultrasonic pulse velocity under elevated temperatures}

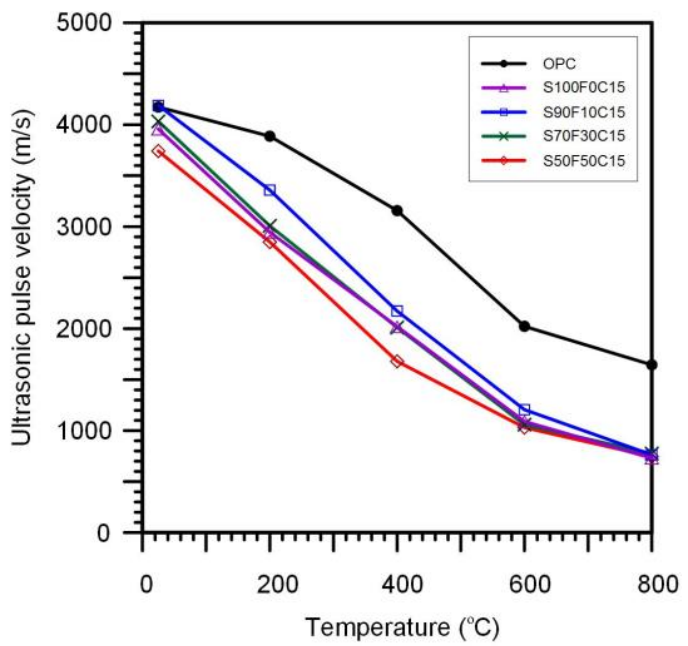

Figure 4. UPV changes in the mortar exposed to elevated temperatures.

Fig. 4 plots results from ultrasonic pulse velocity tests on the mortars after exposed to the elevated temperatures ranging from $200{ }^{\circ} \mathrm{C}$ to $800{ }^{\circ} \mathrm{C}$ at the mortar age of 28 days. At ambient temperature, the UPV result of OPC and S90F10C15 was equivalent approximately $4180 \mathrm{~m} / \mathrm{s}$. This result proved that the compressive strength of mortar with additional fly ash by $10 \%$ gained the better strength than the other SFC mortars. When the mortars were subjected to the elevated temperatures, the UPV decreased significantly. The ultrasonic pulse velocity of SFC mortars at $800{ }^{\circ} \mathrm{C}$ fell down at one point with the reduction by $80 \%$. As temperature rises, induction of microcracks as a result of degradation of calcium silicate hydrate and portlandite and also formation of $\mathrm{CaO}$ crystals during the cooling period may have loosened the microstructure [12]. In general, the microstructures of the specimens that were used in the study deteriorated due to increasing temperature, resulting in decreasing UPV values, especially at $800^{\circ} \mathrm{C}$.

\subsection{Residual compressive strength}

The percentages of residual compressive strengths of OPC and SFC mortars at different elevated temperatures were described in Fig. 5. It should be noted that $\mathrm{X}$-axis named S100, S90, S70 and S50 stands for mixes S100F0C15, S90F10C15 and so on. From Fig. 5, the enhancement in compressive strength occurred in OPC and mix S50F50C 15 that exposed at $200{ }^{\circ} \mathrm{C}$ by $1.9 \%$ and $12.7 \%$, respectively. In the scope of SFC content, S50F50C15 mixture showed the lowest compressive strength and the highest was achieved by S90F10C15 mixture by slight difference of $20 \%$. Above $200{ }^{\circ} \mathrm{C}$, the compressive strength reduced gradually. A declining trend in residual compressive strength was observed as temperature was elevated to $800{ }^{\circ} \mathrm{C}$. This may be attributed to the induction of cracks as a result of evaporation of physically combined water as well as bound water from calcium silicate hydrate [12].

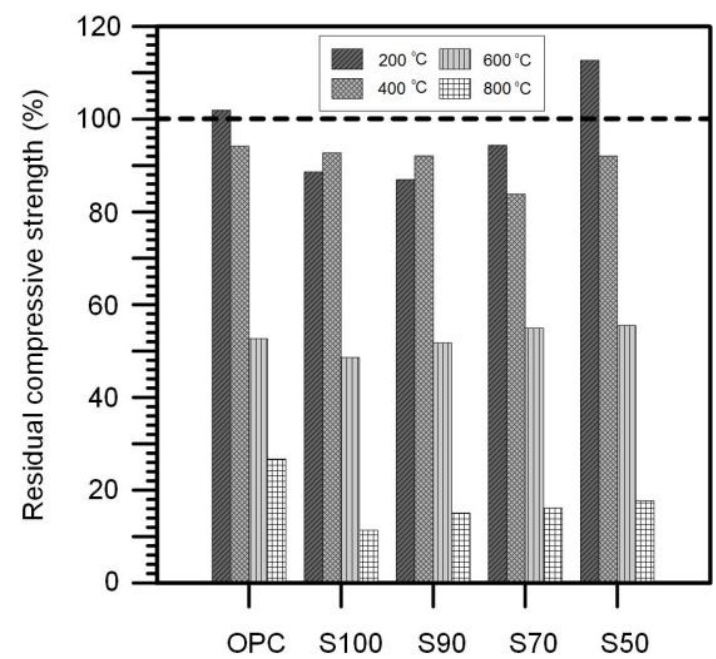

Figure 5. Residual compressive strength of OPC and SFC mortars at different elevated temperatures.

When the mortars heated up to $400{ }^{\circ} \mathrm{C}$, mixes S100F0C15 and S90F10C15 showed a good durability as the corresponding compressive strengths exceeded the compressive strengths when it was subjected to $200{ }^{\circ} \mathrm{C}$. The residual compressive strengths were approximately $92.4 \%$ for the aforementioned mixes. The comparable result was also found interestingly on S50F50C15 mixture. The major strength loss occurred after $600{ }^{\circ} \mathrm{C}$. In this case, the presence of surface microcracks was initially observed in the specimens. As the high 
temperature of $600{ }^{\circ} \mathrm{C}$ was applied to the mortars, the dramatic reduction was initially occurred with the substantial difference up to $44.2 \%$ compared with the residual compressive strength at $400{ }^{\circ} \mathrm{C}$. Both OPC and SFC mortars lose approximately 48.6 to $55.5 \%$ of their compressive strength at temperature of $600{ }^{\circ} \mathrm{C}$. In the other hand, when the mortars were exposed to $800{ }^{\circ} \mathrm{C}$, the test results showed that the strength reduction was significant and the compressive strengths were incredibly low. The residual strength of SFC mortar was measured in the range of $11.4-17.7 \%$ at $800{ }^{\circ} \mathrm{C}$. As a result, SFC mortars still can resist the load with the acceptable strength loss and show good durability below $400{ }^{\circ} \mathrm{C}$, however above this limit, the strength is considerably low due to the formation of cracks.

\section{Conclusions}

The addition of fly ash by $10-30 \%$ with the fixed CFBC fly ash amount of $15 \%$ was found to increase the compressive strength up to $30 \mathrm{MPa}$. Ultrasonic pulse velocity and thermal conductivity tests proved that SFC mortar with $90 \%$ slag content showed better properties with denser microstructure and good heat transfer. After exposed to elevated temperatures, the mass losses of mortar were found in the range of $6.0-8.7 \%$ as temperature rises from 200 to $600{ }^{\circ} \mathrm{C}$ and $12.4 \%$ when exposed to $800{ }^{\circ} \mathrm{C}$. For all mixes, the major strength loss occurred after $600{ }^{\circ} \mathrm{C}$ with the residual compressive strength approximately by $44.2 \%$. Furthermore, the $12.7 \%$ increased compressive strength was found at 200 ${ }^{\circ} \mathrm{C}$ with the utilization of slag-to-binder ratio equal to 0.5 . The SFC mortars still showed good performance when subjected to $400{ }^{\circ} \mathrm{C}$ with the strength loss of $7.6 \%$ similarly with OPC mortar except mix S70F30C15. Above $400{ }^{\circ} \mathrm{C}$, the strength decreased dramatically up to $88.6 \%$. These results indicate the SFC mortar generates good durability and heat resistance acceptably below $400{ }^{\circ} \mathrm{C}$. For future work, it is recommended that further investigation is carried out to examine the microstructure of the hardened paste after subjected to elevated temperatures and ensure the effects of adding various amount of CFBC fly ash on long-term strength development.

\section{Acknowledgment}

The authors would like to gratefully acknowledge the financial supports from both the Ministry of Science and Technology through the grants of MOST 103-2221-E-011-078-MY3 and National Taiwan University of Science and Technology (NTUST) to conduct this experimental study.

\section{References}

1. C.-T. Chen, H.-A. Nguyen, T.-P. Chang, T.-R. Yang, T.-D. Nguyen, Constr. Build. Mater. 76, 264-272 (2015)

2. T.-D. Nguyen, T.-P. Chang, C.-T. Chen, Constr. Build. Mater. 63, 40-48 (2014)

3. X.-G. Li, Q.-B. Chen, K.-Z. Huang, B.-G. Ma, B. Wu, Constr. Build. Mater. 36, 182-187 (2012)

4. M. Chi, Constr. Build. Mater. 123, 565-573 (2016)

5. T. Wu, M. Chi, R. Huang, Constr. Build. Mater. 66, 172-180 (2014)

6. H.-A. Nguyen, T.-P. Chang, J.-Y. Shih, C.-T. Chen, T.-D. Nguyen, Constr. Build. Mater. 106, 670-677 (2016)

7. H.-A. Nguyen, T.-P. Chang, J.-Y. Shih, C.-T. Chen, T.-D. Nguyen, Constr. Build. Mater. 91, 208-215 (2015)

8. H.-A. Nguyen, T.-P. Chang, J.-Y. Shih, C.-T. Chen, T.-D. Nguyen, Constr. Build. Mater. 102, 239-243 (2015)

9. S. A. Omer, R. Demirboga, W. H. Khushefati, Constr. Build. Mater. 94, 189-195 (2015)

10. E. Horszczaruk, P. Sikora, K. Cendrowski, E. Mijowska, Constr. Build. Mater. 137, 420-431 (2017)

11. A. Nadeem, S. A. Memon, T. Y. Lo, Constr. Build. Mater. 38, 338-347 (2012)

12. N. Farzadnia, A. A. A. Ali, R. Demirboga, M. P. Anwar, Constr. Build. Mater. 43, 469-479 (2013) 